\title{
Tuning the Bandgap in Silver Bismuth lodide Materials by Partly Substituting Bismuth with Antimony for Improved Solar Cell Performance
}

\author{
Huimin Zhu, "Axel Erbing," Hua Wu, Gabriel J. Man, Soham Mukherjee, Chinnathambi Kamal, \\ Malin B. Johansson, Håkan Rensmo, Michael Odelius, * and Erik M. J. Johansson*
}

Cite This: ACS Appl. Energy Mater. 2020, 3, 7372-7382

Read Online

ACCESS | Lلll Metrics \& More | 回 Article Recommendations | st Supporting Information

ABSTRACT: Silver bismuth iodide $(\mathrm{Ag}-\mathrm{Bi}-\mathrm{I})$ light absorbers are interesting candidates as lead-free and low-toxic metal-halide materials for solar cell applications. In this work, the partial exchange of bismuth, $\mathrm{Bi}$, with antimony, $\mathrm{Sb}$, is investigated in samples prepared from a solution targeting stoichiometry $\mathrm{AgBi}_{2} \mathrm{I}_{7}$. Samples with a gradually increased exchange of $\mathrm{Bi}$ by $\mathrm{Sb}$ are prepared and light absorption measurements show that the absorption edge is gradually blueshifted with increasing the amount of Sb. This trend in the shift in combination with the X-ray diffraction and $\mathrm{X}$-ray photoelectron spectroscopy measurements, suggest that new materials with a mixture of $\mathrm{Sb}$ and $\mathrm{Bi}$ are formed. The density functional theory based electronic structure calculations reproduce the trend observed in the experiments when including spin-orbit coupling, which indicates the importance of relativistic effects in these materials. X-ray photoelectron spectroscopy is used to characterize the materials, and confirms the exchange of $\mathrm{Bi}$ to $\mathrm{Sb}$ in the samples. When $\mathrm{Sb}$ is included in the material, the grain size changes between 50 and $200 \mathrm{~nm}$ and the solar cell performance also changes. An optimal power conversion efficiency with

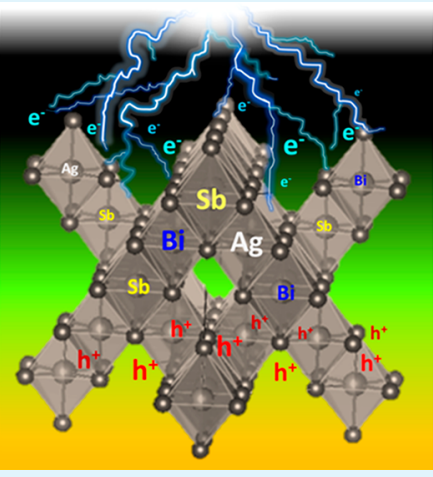
excellent reproducibility and stability is obtained for a solar cell with the ratio of $\mathrm{Sb} / \mathrm{Bi}$ equal to 3 .

KEYWORDS: lead-free light absorbers, silver bismuth iodide, bismuth, antimony, photovoltaic, metal halide

\section{INTRODUCTION}

Lead $(\mathrm{Pb})$ halide perovskite solar cells have shown a rapid development, and the record for power conversion efficiency (PCE) has recently reached $25.2 \%{ }^{1}$ This has been developed from the first publication of $\mathrm{Pb}$-perovskite solar cells with a PCE of $3.8 \%$ in $2009^{2}$ and the first solid-state $\mathrm{Pb}$-perovskite solar cell devices with a PCE of around $10 \%$ in 2012.,4 Moreover, a tandem solar cell with $\mathrm{Pb}$-perovskite and silicon is a promising concept to obtain further increased efficiency. $\mathrm{Pb}$ perovskites can absorb light up to around $800 \mathrm{~nm}$ and silicon can absorb light up to around $1100 \mathrm{~nm}$ in the near-infrared region. Therefore, the silicon solar cell can compensate for the absorption disadvantage of the $\mathrm{Pb}$-perovskite solar cell in the near-infrared region. Living up to the expectations, the record PCE of the perovskite-silicon tandem solar cell now is $29.1 \%$, which is higher than the previous record of $28 \%$ from the Oxford PV Company. ${ }^{5,6}$

One problem with the $\mathrm{Pb}$-perovskites is the toxicity of lead. In attempts to address this problem, many investigations have been performed with other less toxic cations, which could replace $\mathrm{Pb}$, for example, tin $\left(\mathrm{Sn}^{2+}\right),{ }^{6}\left(\mathrm{Sn}^{4+}\right)^{7}$ germanium $\left(\mathrm{Ge}^{2+}\right),{ }^{8,9}$ bismuth $\left(\mathrm{Bi}^{3+}\right),{ }^{10-12}$ antimony $\left(\mathrm{Sb}^{3+}\right){ }^{13}$ titanium $\left(\mathrm{Ti}^{4+}\right),{ }^{14}$ etc. A recent publication by Nitin P. Padture and coworkers shows that one native-oxide passivation layer ( $\mathrm{Sn}$ doped $\mathrm{GeO}_{2}$ ) can boost the $\mathrm{CsSn}_{0.5} \mathrm{Ge}_{0.5} \mathrm{I}_{3}$ efficiency to $7.11 \%$ and stability for $500 \mathrm{~h}$ under continuous one sun illumination. ${ }^{15}$ Other investigations show that the 2D PEAI mixed 3D FASnI 3 can result in a promising solar cell efficiency (9\%); however, the stability still is not as good as for the Pbperovskite solar cell. ${ }^{16,17}$ The record efficiency for a tin based perovskite is $9.6 \%$, which is achieved by adding $1 \%$ of $\mathrm{EDAI}_{2}$ and $20 \% \mathrm{GA}^{+}$to $\mathrm{FASnI}_{3}{ }^{18}$ Though promising results have been obtained on $\mathrm{Sn}$ based perovskite solar cells, the $\mathrm{Sn}^{2+}$ ion is easily oxidized to a higher valence state ${ }^{19}$ and the toxicity of Sn based compounds needs to be carefully addressed. ${ }^{20} \mathrm{Bi}$ and $\mathrm{Sb}$ can be stabilized in the $3+$ valence state, thereby avoiding the charge fluctuation issues. They may therefore be better candidates than $\mathrm{Sn}^{2+}$ and $\mathrm{Ge}^{2+}$ and may in addition be more environmentally friendly. Biand $\mathrm{Sb}$ could therefore be promising cations to replace $\mathrm{Pb}$ under the consideration of low toxicity, high stability and potentially promising photovoltaic properties. Materials based on these two cations have been explored recently, for example $\mathrm{A}_{3} \mathrm{Bi}_{2} \mathrm{I}_{9} \quad(\mathrm{~A}=\mathrm{Cs}$,

Received: April 3, 2020

Accepted: July 16, 2020

Published: July 16, 2020 
methylammonium (MA), ${ }^{10}$ formamidinium $\left.(\mathrm{FA})^{21}\right), \mathrm{A}_{3} \mathrm{Sb}_{2} \mathrm{I}_{9}$ $(\mathrm{A}=\mathrm{Cs}, \mathrm{Rb}, \mathrm{K}),{ }^{22} \mathrm{Cs}_{2} \mathrm{AgBiB}_{6}(\mathrm{~B}=\mathrm{Br}, \mathrm{Cl}),{ }^{23-27}$ and $\mathrm{Ag}-$ Bihalide materials. ${ }^{28-34}$ Since $\mathrm{Sb}^{3+}\left(5 \mathrm{~s}^{2} 5 \mathrm{p}^{0}\right)$ and $\mathrm{Bi}^{3+}\left(6 \mathrm{~s}^{2} 6 \mathrm{p}^{0}\right)$ have the similar electronic configuration as $\mathrm{Pb}^{2+}$, both of them can possibly replace $\mathrm{Pb}$. However, the different charge and size of the ions affect the crystal structure and induce defects, thereby modifying the electronic structure and the carrier properties of the light absorbers. ${ }^{35}$ The Bi based halides usually have an indirect bandgap but some $\mathrm{Sb}$ based halides, like $\mathrm{Cs}_{3} \mathrm{Sb}_{2} \mathrm{I}_{9}$, have a nearly direct band gap for light absorption. ${ }^{36}$ Recently, a series of $\mathrm{Ag}-\mathrm{Bi}-\mathrm{I}-$ based materials, which can be derived simply by changing the $\mathrm{AgI}$ and $\mathrm{BiI}_{3}$ precursor ratio have been explored. ${ }^{2,30,37,38}$ Both $\mathrm{Ag}_{2} \mathrm{BiI}_{5}, \mathrm{AgBi}_{2} \mathrm{I}_{7}$, and $\mathrm{Ag}_{3} \mathrm{BiI}_{6}$ showed very promising photovoltaic performances with PCE over $2 \%{ }^{28,29,39} \mathrm{AgBi}_{2} \mathrm{I}_{7}$ in particular forms a very homogeneous film that is a crucial aspect for solar cell devices fabrication. $^{29,30}$

In this work, we investigate the possibility of partly replacing $\mathrm{Bi}$ with $\mathrm{Sb}$ in $\mathrm{AgBi}_{2} \mathrm{I}_{7}$, and study the effect of this replacement on the optical, structural, and photoelectrical properties. The stoichiometry of each sample has been defined by their precursor ratios. Starting from the $\mathrm{AgBi}_{2} \mathrm{I}_{7}$ material, which has good film-forming properties, we gradually replace an increasing fraction of $\mathrm{Bi}$ with $\mathrm{Sb}$ in the materials. Our investigations show that partial replacement of $\mathrm{Bi}$ with $\mathrm{Sb}$ is feasible and is a viable route to modify the optical properties of the material. These findings are a key contribution to more rational material designs of future, with improved photovoltaic properties.

\section{RESULTS AND DISCUSSION}

A series of samples, $\mathrm{AgBi}_{2} \mathrm{I}_{7}, \mathrm{AgBi}_{1.5} \mathrm{Sb}_{0.5} \mathrm{I}_{7}, \mathrm{AgBiSbI}_{7}$, and $\mathrm{AgBi}_{0.5} \mathrm{Sb}_{1.5} \mathrm{I}_{7}$, as calculated from the precursor ratios, were prepared by spin coating the precursor solutions on $\mathrm{TiO}_{2} /$ FTO glass substrates. The detailed preparation of the samples is described in the Experimental Methods below. The surface morphologies of the samples were studied with scanning electron microscopy (SEM) and the images are shown in Figure 1.

Figure $1 \mathrm{a}, \mathrm{c}$, e, and g contains small magnification images, and Figure $1 \mathrm{~b}, \mathrm{~d}, \mathrm{f}$, and $\mathrm{h}$ contains large magnification images. Figure $1 \mathrm{a}$ and $\mathrm{b}$ shows the $\mathrm{AgBi}_{2} \mathrm{I}_{7}$ samples (without $\mathrm{Sb}$ ). The surface appears homogeneous in a large range (a); however, there exists some pinholes between the grains, which are in the size ranging from 200 to $250 \mathrm{~nm}$ (b). In Figure 1c and d, smaller crystals are observed, and in panels e and $\mathrm{f}$, again larger crystals are obtained, but with more pinholes between the crystals. In Figure $1 \mathrm{~g}$ and h, both large and small crystals are observed, and the film has less pinholes than the other films. The SEM images therefore clearly demonstrate that the morphology is affected when $\mathrm{Sb}$ is included in the material.

Figure 2a shows the X-ray diffraction (XRD) patterns of the different materials deposited on $\mathrm{TiO}_{2}$ substrates in comparison to bare $\mathrm{TiO}_{2}$. Although a few major Bragg reflections from our samples overlap with $\mathrm{TiO}_{2}$, the reflections around $13^{\circ}, 23.5^{\circ}$, $29.5^{\circ}$, and $42^{\circ}$ for the reference $\mathrm{Ag}-\mathrm{Bi}-\mathrm{I}$ sample can be assigned to (111), (113), (004), and (044) crystal planes for cubic $(\mathrm{F} d \overline{3} \mathrm{~m})$ phase of $\mathrm{AgBi}_{2} \mathrm{I}_{7}{ }^{29}$ After gradual exchange of $\mathrm{Bi}$ atoms with $\mathrm{Sb}$ atoms, very similar XRD patterns are obtained, which shows that the global crystal structures of the materials are very similar. The estimated unit cell parameters decrease with $\mathrm{Sb}$ doping, listed in Table 1 . At extensive exchange of $\mathrm{Bi}$ with $\mathrm{Sb}$, a peak around $22^{\circ}$ can be observed, which could be

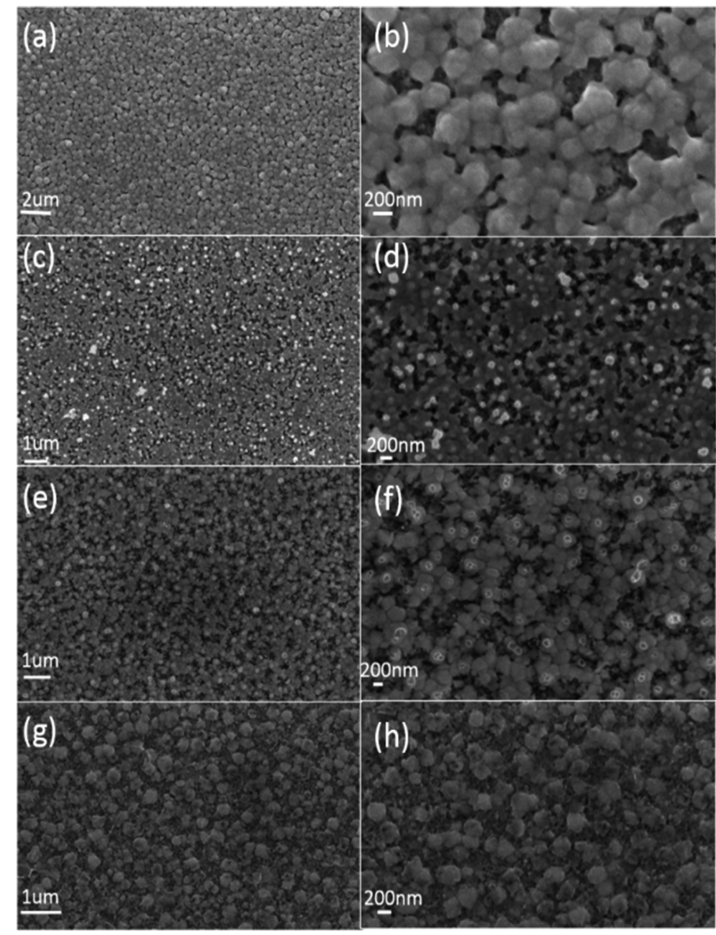

Figure 1. SEM measurement of surface morphologies of $\mathrm{AgBi}_{2} \mathrm{I}_{7}(\mathrm{a}) /$ (b), $\mathrm{AgBi}_{1.5} \mathrm{Sb}_{0.5} \mathrm{I}_{7}$ (c)/(d), $\operatorname{AgBiSbI}_{7}(\mathrm{e}) /(\mathrm{f})$, and $\mathrm{AgBi}_{0.5} \mathrm{Sb}_{1.5} \mathrm{I}_{7}(\mathrm{~g}) /$ (h) in small/large magnification.

attributed to AgI. The XRD pattern for the $\mathrm{AgSb}_{2} \mathrm{I}_{7}$ sample annealed to $100^{\circ} \mathrm{C}$ for 5 min (black line in Figure 2) is similar to the XRD pattern for $\mathrm{AgBi}_{2} \mathrm{I}_{7}$, which shows that the pure $\mathrm{AgSb}_{2} \mathrm{I}_{7}$ material has a similar structure to $\mathrm{AgBi}_{2} \mathrm{I}_{7}$. However, if the pure $\mathrm{AgSb}_{2} \mathrm{I}_{7}$ sample was further annealed to $125{ }^{\circ} \mathrm{C}$ for 25 min (red line in Figure 2) the color changes to yellow and the crystal structure is obviously damaged by the high annealing process, because peaks around $12^{\circ}$ and $28^{\circ}$ in the XRD are missing from the "Sb2 Yellow" sample, and only those related to AgI the underlying such as $22.5^{\circ}$ and $24.2^{\circ}$ remain. Since cubic symmetry is retained for the samples in the entire solid solution regime, we could obtain the approximate composition of different samples simply by fitting the shifts of the Bragg reflections for the $h+k+l=3 n(n=1-4)$ family of lattice planes. The XRD results suggest successful incorporation of $\mathrm{Sb}$ into the material, see Figure S1.

$\mathrm{X}$-ray photoelectron spectroscopy (XPS) and hard X-ray photoelectron spectroscopy (HAXPES) were used to investigate the composition of the samples at the surface and slightly deeper into the bulk, respectively. The results from the HAXPES and XPS measurements are presented in Figures S2 and S3. The atomic ratios of different atoms were derived from the area divided by their relative cross-section factors. ${ }^{40}$ The fitted and expected results (from the precursor ratios), which are given in Table S2, reveal crucial details about surface composition. From the XPS measurements the $\mathrm{Ag}:(\mathrm{Bi}+\mathrm{Sb})$ is close to 1:2, as expected from a precursor ratio 1:2 for AgI and $\mathrm{BiI}_{3}$. The trend in atomic ratios of bismuth and antimony estimated from the XPS is therefore in agreement with the expected trend in $1-2-7$ stoichiometry of the $\mathrm{Ag}-\mathrm{Bi}-\mathrm{I}$ series. These measurements therefore also support the conclusion that materials with a mix of $\mathrm{Sb}$ and $\mathrm{Bi}$ are obtained, in line with our results from XRD. Second, unlike a global structural probe like $\mathrm{XRD}$, we find a stronger degree of composition variation 


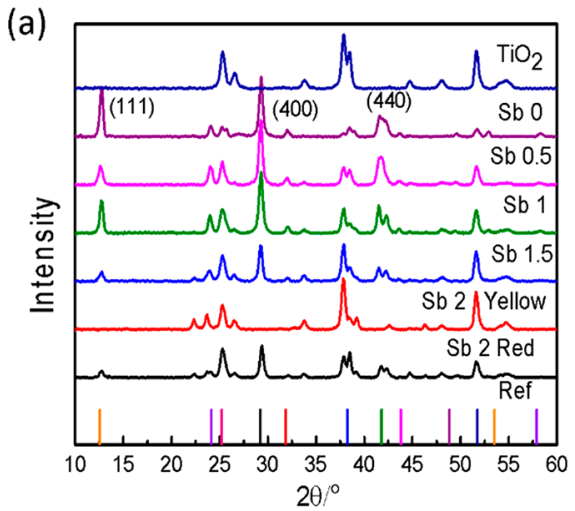

(b)

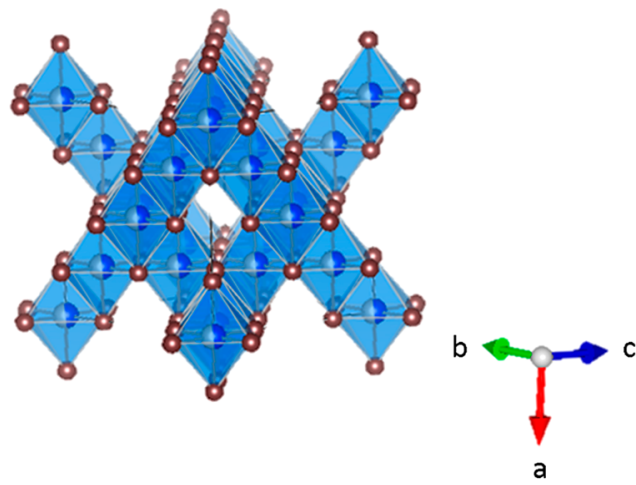

Figure 2. (a) $\mathrm{XRD}$ patterns of $\mathrm{TiO}_{2}$ and $\mathrm{AgBi}_{2} \mathrm{I}_{7}$ (dark blue, and purple), $\mathrm{AgBi}_{1.5} \mathrm{Sb}_{0.5} \mathrm{I}_{7}, \mathrm{AgBiSbI}_{7}$, and $\mathrm{AgBi}_{0.5} \mathrm{Sb}_{1.5} \mathrm{I}_{7}$ (pink, green and blue), and $\mathrm{AgSb}_{2} \mathrm{I}_{7}$ (red and black). The cubic structure of the $\mathrm{AgBi}_{2} \mathrm{I}_{7}$ (b). Silver and blue balls in octahedral are Ag or Bi; red balls are iodine atoms.

Table 1. Indirect Band Gap, Direct Band Gap, and $\sqrt{\frac{\alpha\left(E_{\text {gap }}\right)}{\alpha\left(1.02 E_{\text {gap }}\right)}}$ Values Derived from the Experiments, and the Calculated Indirect Band Gap and Direct Band Gap of $\mathrm{AgBi}_{2-x} \mathrm{Sb}_{x} \mathrm{I}_{7}(x=0.0,0.5,1.0,1.5,2.0)$ with and without the Inclusion of SOC Effects and the Cell Parameter of the Optimized Unit Cells

\begin{tabular}{|c|c|c|c|}
\hline \multirow[b]{3}{*}{$x$} & \multirow{3}{*}{$\frac{\text { indirect band gap }(\mathrm{eV})}{\exp }$} & \multirow[b]{2}{*}{ direct band gap $(\mathrm{eV})$} & \multirow{2}{*}{$\sqrt{\frac{\alpha\left(E_{\text {gap }}\right)}{\alpha\left(1.02 E_{\text {gap }}\right)}}$} \\
\hline & & & \\
\hline & & $\exp$ & $\exp$ \\
\hline 0.0 & 1.61 & 1.79 & 0.98 \\
\hline 0.5 & 1.64 & 1.90 & 0.92 \\
\hline 1.0 & 1.65 & 1.91 & 0.92 \\
\hline 1.5 & 1.74 & 2.00 & 0.90 \\
\hline 2.0 & 1.98 & 2.23 & 0.94 \\
\hline$x$ & with SOC & with SOC & ell parameter $(\AA)$ \\
\hline 0.0 & 1.012 along $\Gamma-\mathrm{R}$ & 1.123 at $\Gamma$ & 12.372 \\
\hline 0.5 & 1.057 along $\Gamma-\mathrm{R}$ & 1.148 at $\Gamma$ & 12.347 \\
\hline 1.0 & 1.181 along $\Gamma-\mathrm{R}$ & 1.303 at $\Gamma$ & 12.321 \\
\hline 1.5 & 1.117 along $\Gamma-\mathrm{R}$ & 1.255 at $\mathrm{R}$ & 12.286 \\
\hline 2.0 & 1.283 along $\Gamma-\mathrm{R}$ & 1.394 at $\mathrm{R}$ & 12.260 \\
\hline$x$ & without SOC & without SOC & ell parameter $(\AA)$ \\
\hline 0.0 & 1.506 along $\Gamma-\mathrm{R}$ & 1.616 at $\mathrm{R}$ & 12.372 \\
\hline 0.5 & 1.498 along $\Gamma-\mathrm{R}$ & 1.599 at $\mathrm{R}$ & 12.347 \\
\hline 1.0 & 1.407 along $\Gamma-\mathrm{R}$ & 1.529 at $\mathrm{R}$ & 12.321 \\
\hline 1.5 & 1.396 along $\Gamma-\mathrm{R}$ & 1.506 at $\mathrm{R}$ & 12.286 \\
\hline 2.0 & 1.364 along $\Gamma-\mathrm{R}$ & 1.476 at $\mathrm{R}$ & 12.260 \\
\hline
\end{tabular}

between the samples, suggestive of surface effects. Third, the amount of iodide in the samples estimated from XPS and HAXPES is clearly lower than expected from the precursor ratios. This may be an indication of loss of iodide in the form of molecular iodine at the surface region of the samples. This low iodide content may also affect the device properties, since iodide vacancy defects may influence the electronic properties. ${ }^{39,41}$ We also observe finite density of states at the Fermi edge in HAXPES, which is most likely can be attributed to metallic Bi impurities. However, XRD (Figure 2a) did not capture any such signatures of metallic $\mathrm{Bi}$, additional impurity phases or alternate Ag-Bi-I compositions, except for AgI in Sb-rich compositions. Therefore, the observed composition fluctuations could be solely a surface phenomenon or atomic clusters smaller than by bulk sensitivity of XRD or amorphous in nature. Nonetheless, the system always preserves its global cubic symmetry, as one expects also from an Ag-deficient $\mathrm{AgBiI}_{4}$-type structure, ${ }^{42}$ which crystallizes in cubic symmetry.

Figure $3 \mathrm{a}$ shows the absorptance spectra of the $\mathrm{AgBi}_{2} \mathrm{I}_{7}$, $\mathrm{AgBi}_{1.5} \mathrm{Sb}_{0.5} \mathrm{I}_{7}, \mathrm{AgBiSbI}_{7}, \mathrm{AgBi}_{0.5} \mathrm{Sb}_{1.5} \mathrm{I}_{7}$, and $\mathrm{AgSb}_{2} \mathrm{I}_{7}$ samples. All the samples were prepared on quartz glass and $\mathrm{TiO}_{2}$, see Experimental Methods for further details. The maximum absorptance of the three $\mathrm{Sb}$-mixed samples are around $85 \%$, which is as high as absorbance for the $\mathrm{AgBi}_{2} \mathrm{I}_{7}$ sample. The absorptance spectra are quite flat without any extra peaks between 300 and $650 \mathrm{~nm}$. The absorption edge is gradually blue-shifted when an increased amount of $\mathrm{Bi}$ is partly exchanged to $\mathrm{Sb}$, which suggests that single phase materials containing both $\mathrm{Bi}$ and $\mathrm{Sb}$ are formed and not a mixture of separate $\mathrm{AgBi}_{2} \mathrm{I}_{7}$ and $\mathrm{AgSb}_{2} \mathrm{I}_{7}$ phases. Figure $3 \mathrm{~b}$ shows a photo of the $\mathrm{AgBi}_{2} \mathrm{I}_{7}, \mathrm{AgBi}_{1.5} \mathrm{Sb}_{0.5} \mathrm{I}_{7}, \mathrm{AgBiSbI}_{7}, \mathrm{AgBi}_{0.5} \mathrm{Sb}_{1.5} \mathrm{I}_{7}$, and of $\mathrm{AgSb}_{2} \mathrm{I}_{7}$ (light red and light yellow) samples, respectively (from left to right), and a clear gradual change of the color can be observed.

In Figure $3 \mathrm{c}$ and $\mathrm{d}$, the indirect bandgap and direct bandgap are determined by plotting $(a \cdot d \cdot h v)^{1 / n}$ versus $h v$ for the $n$ values $\left(n=\frac{1}{2}\right.$ or 2$)$, respectively. The indirect bandgaps and direct bandgaps are listed in Table 1 . As evident from the blueshift of the edge in the absorptance spectra the bandgaps become larger with more $\mathrm{Sb}$ content. To study low energy defects and sub-bands of these films, Urbach tail effects are investigated using the background of Tauc plots, shown in Figure $3 c$ and $d$. In the work of Birnie et al., ${ }^{43}$ a method to the quantify magnitude of the Urbach tail called the "near edge absorptivity ratio" (NEAR) is introduced. Following this method for an indirect transition, the NEAR is defined as the ratio $\left(\sqrt{\frac{\alpha\left(E_{\text {gap }}\right)}{\alpha\left(1.02 E_{\text {gap }}\right)}}\right)$, where $a\left(E_{\text {gap }}\right)$ is the value at the bandgap position (the intersection of the $x$-axis and the tangent); $a\left(1.02 E_{\text {gap }}\right)$ is arbitrarily chosen to be $2 \%$ higher energy than the bandgap, which is represented by the dashed lines in the figure. For an ideal light absorber without the Urbach tail, the NEAR value should be zero, which means the material is defect-free without sub bandgap states. For the indirect transition, the NEAR value of $\mathrm{AgBi}_{2} \mathrm{I}_{7}$ is the largest and the $\mathrm{Sb}$-mixed materials show smaller NEAR values, which suggests creation of less bandgap states after mixing $\mathrm{Bi}$ with $\mathrm{Sb}$. The $\mathrm{AgBi}_{0.5} \mathrm{Sb}_{1.5} \mathrm{I}_{7}$ composition shows smaller NEAR value than the other $\mathrm{Sb}$ mixed materials, which suggest that this composition may have the lowest amount of bandgap states. 
(a)

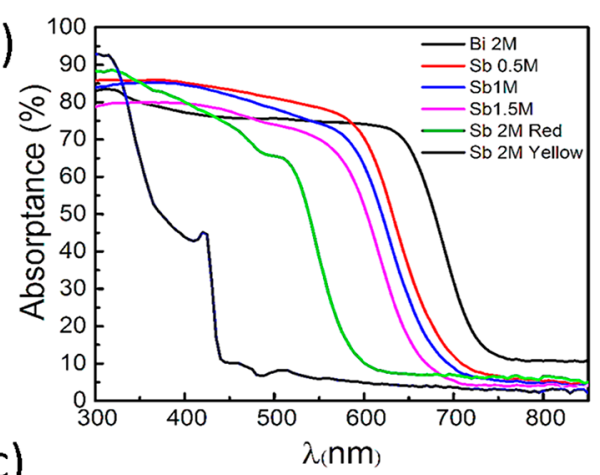

(c)

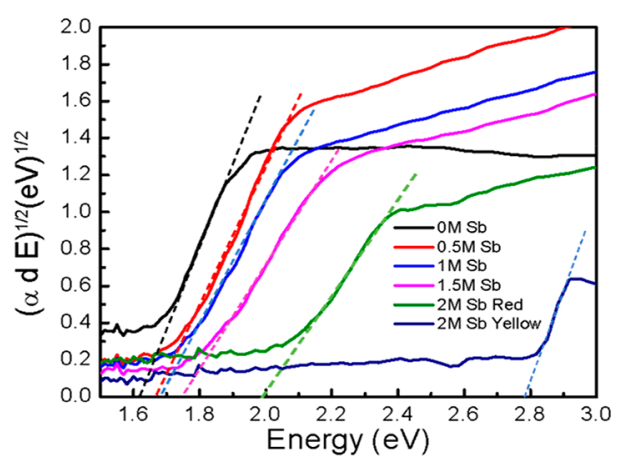

(b)

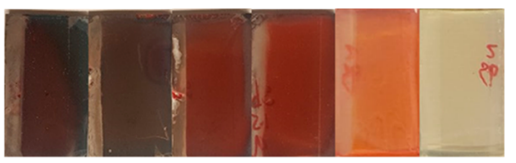

(d)

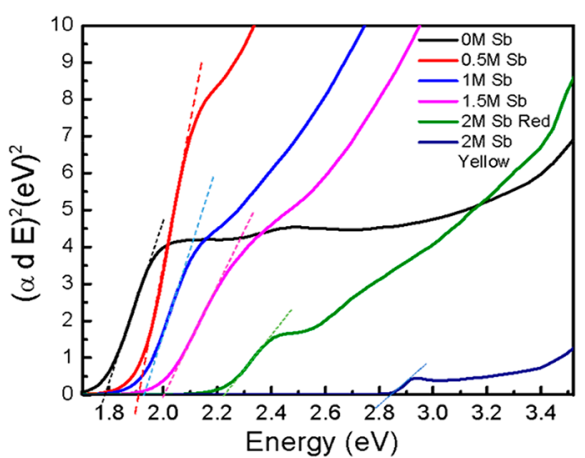

Figure 3. (a) Absorptance, (b) annealed films on meso- $\mathrm{TiO}_{2}$, and the indirect (c) and direct (d) band gap Tauc plots of samples with $0,0.5,1,1.5$, and $2 \mathrm{M} \mathrm{Sb}$.

To gain microscopic understanding of the investigated systems and augment the Experimental Methods, we performed electronic structure calculations using density functional theory (DFT). For this purpose, the electronic band structure and the density of states of the material were calculated (details are given below). From the projected density of states (PDOS), the elemental contributions to bands, including the principle quantum number of the orbitals, can be found. The PDOS for the different samples are presented in Figure $4 \mathrm{~b}$. The most prominent features in the valence band are from I 5p states together with $\mathrm{Ag} 4 \mathrm{~d}$ states, which are both present at the top of the band. Interestingly, the feature corresponding to PDOS of $\mathrm{Ag} 4 \mathrm{~d}$ states looks very similar for all compositions which suggests that the $\mathrm{Ag}-\mathrm{I}$ interaction is not strongly influenced by the replacement of $\mathrm{Bi}$ by $\mathrm{Sb}$. Bi $6 \mathrm{p}$ and $\mathrm{Sb} 5 \mathrm{p}$ states are also present at lower orbital energies, together with smaller contributions from $6 \mathrm{~s}$ and $6 \mathrm{~d}$ states from $\mathrm{Bi}$ and $5 \mathrm{~s}$ and $5 \mathrm{~d}$ from $\mathrm{Sb}$, respectively, at orbital energies of approximately $-2 \mathrm{eV}$. The splitting of the I $5 p$ peaks around $-2 \mathrm{eV}$ in the composition with higher $\mathrm{Sb}$ suggests that there is a slightly stronger hybridization of this orbital with $\mathrm{Sb} 5 \mathrm{~d}$ states as compared to $\mathrm{Bi} 6 \mathrm{~d}$ states. Thus, as expected, the substitution of $\mathrm{Bi}$ by $\mathrm{Sb}$ atom significantly influences the electronic structure of the $\mathrm{Bi} / \mathrm{Sb}-\mathrm{I}$ network. In the conduction band, antibonding $\mathrm{Bi} 6 \mathrm{p} / \mathrm{Sb} 5 \mathrm{p}$ and I $5 \mathrm{p}$ states constitute the main feature together with weaker I 5s and $5 \mathrm{~d}$. At higher orbital energies, Ag 5s states occur along with halide states.

The band structures are shown in Figure 4c. For all investigated $\mathrm{Bi}-\mathrm{Sb}$ compositions, the system has an indirect band gap in the $\Gamma-\mathrm{R}$ direction, in which $\mathrm{R}$ corresponds to a periodicity of twice the cell parameter along all cell vectors. Without including spin-orbit coupling (SOC) effects in the calculations, the direct band gap is located at $\mathrm{R}$ in all cases. If SOC is included, the band gap is reduced in all cases and for the compositions rich in $\mathrm{Bi}$, the direct band gap shifts from $\mathrm{R}$ to $\Gamma$.

The calculated band gaps, shown in Table 1, exhibit a slight difference between the indirect and direct band gaps. The bandgap slightly decreases with the $\mathrm{Sb}$ content of the material for both the indirect and the direct transitions, which is contrary to the observed experimental trend, for the calculations not taking SOC effects into account. With SOC effects for $\mathrm{Bi}$ and $\mathrm{Sb}$ atoms included, the band gap is substantially reduced for the compositions rich in $\mathrm{Bi}$. It is expected that this effect should be stronger in the heavier elements. More importantly, the band gap trend is reversed, reproducing the experimental composition dependence. The calculations show that SOC has a strong influence on the electronic structure of $\mathrm{AgBi}_{2-x} \mathrm{Sb}_{x} \mathrm{I}_{7}$ systems and is directly responsible for the increase in band gap with increasing $\mathrm{Sb}$ content. In all cases, the calculated values are lower than the experimental values because of limitations of the PBE functional. SOC reduces the band gap even further giving an even larger difference, as previously seen in similar systems. ${ }^{41}$ The effects of temperature was also briefly investigated for the pure materials, that is, $\mathrm{AgBi}_{2} \mathrm{I}_{7}$ and $\mathrm{AgSb}_{2} \mathrm{I}_{7}$, through molecular dynamics, which only had minor effects on the band gap.

Solar cells based on the mixed metal-halide light absorbers on mesoporous $\mathrm{TiO}_{2}$ structure were fabricated to study the effect of mixed $\mathrm{Bi} / \mathrm{Sb}$ content on the photovoltaic properties. A schematic diagram of the solar cell structure and of the approximate energy levels are shown in Figure 5a. Poly[ $[4,8-$ bis [(2-ethylhexyl) oxy] benzo[ 1,2-b:4,5-b'] dithiophene-2,6diyl] [3-fluoro-2-[(2-ethylhexyl) carbonyl] thieno[3,4-b]thiophenediyl]] (PTB7) was used as the hole transport material (HTM). A schematic picture of the approximate energy levels of different layers can be seen in Figure $5 \mathrm{~b}$. The valence band of $\mathrm{AgBi}_{2} \mathrm{I}_{7}$ is approximately $-6.2 \mathrm{eV},{ }^{30}$ which is a rather low energy compared to many of the standard HTM 
(a)

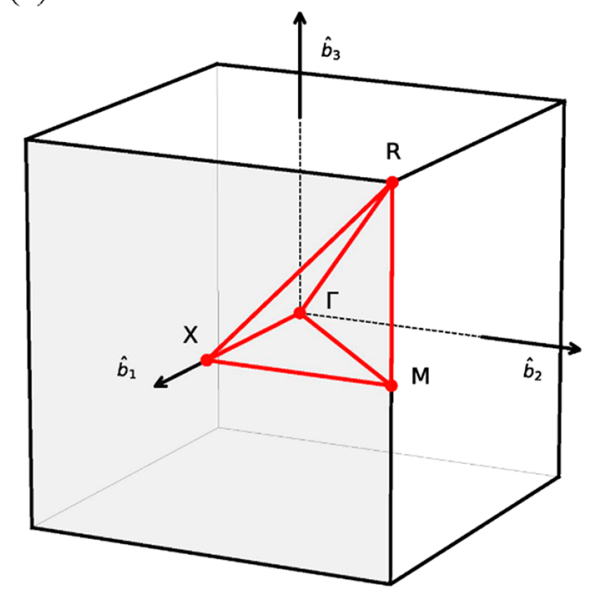

(b)

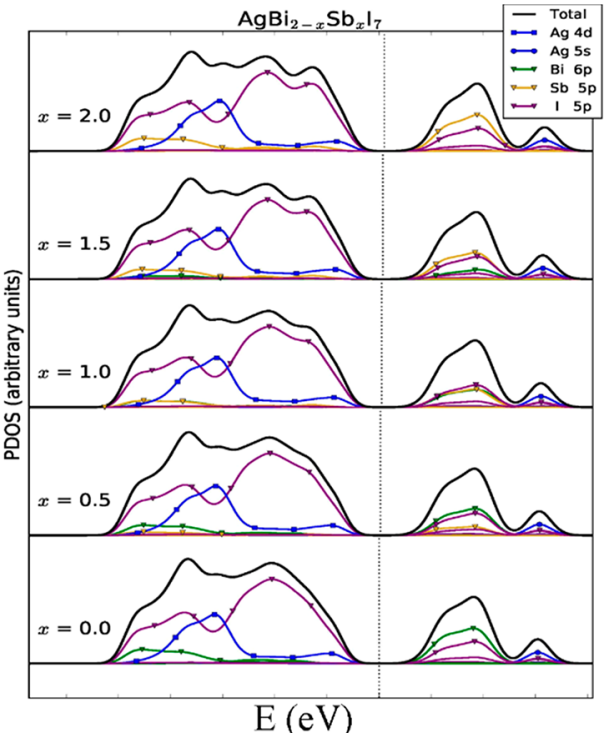

(c)
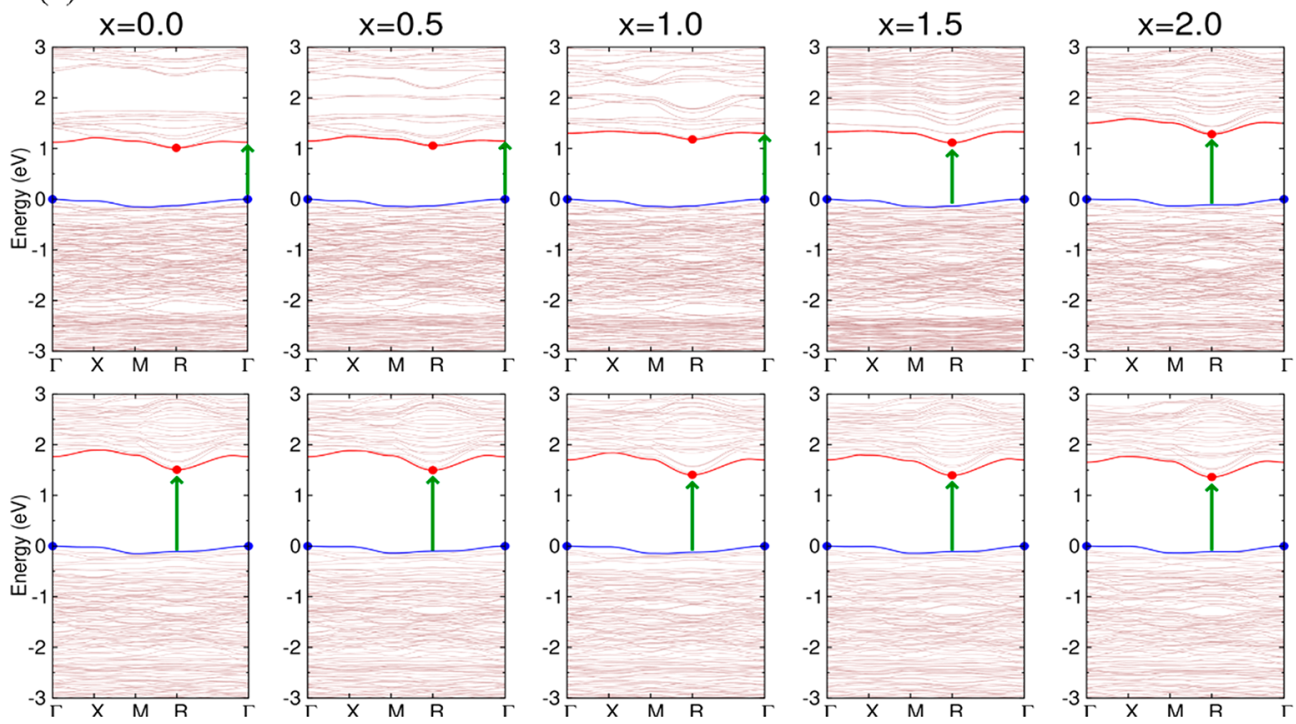

Figure 4. Brillouin zone of a simple cubic crystal (a), PDOS diagram (b), and electronic band structure of $\mathrm{AgBi}_{2-x} \mathrm{Sb}_{x} \mathrm{I}_{7}(x=0.0,0.5,1.0,1.5,2.0)$ (c) have been plotted along high symmetric points. Top and bottom panels contain results obtained by GGA (PBE) + SOC and GGA (PBE) calculations. The highest valence and lowest conduction bands are highlighted in blue and red colors, respectively. The colored circles on these two bands represent the location of valence and conduction band edges. Green arrow indicates the onset of direct band transition.

(a)

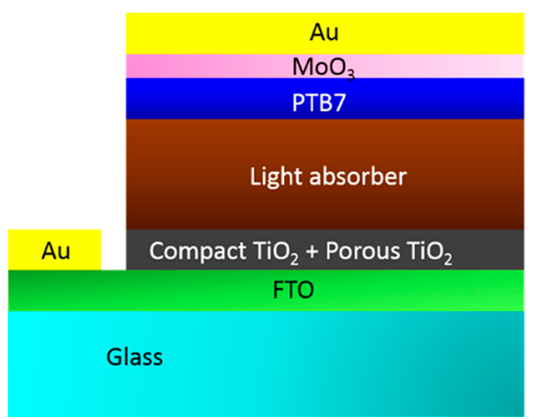

(b)

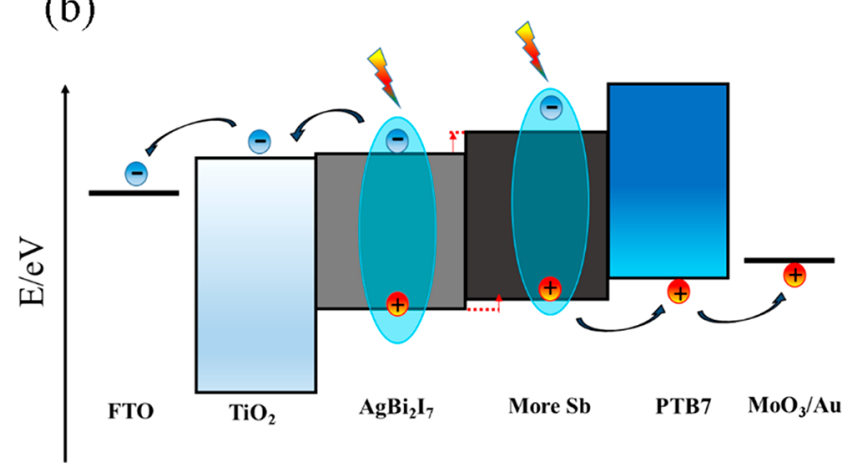

Figure 5. Schematic diagram of layers in the solar cell structure (a) and approximate energy levels of the different layers (b).

materials, and therefore PTB7 was chosen as HTM, since it has a rather low highest occupied molecular orbitals (HOMO) level $(-5.4 \mathrm{eV})$ compared to P3HT or spiro-OMeTAD, which has a HOMO level around $-5.1 \mathrm{eV}$. To avoid recombination issues between the metal-halide layer and the gold layer, if pinholes exist in the HTM layer, $\mathrm{MoO}_{3}$ was used as the buffer layer on top of the HTM layer. A SEM cross-section of the champion device is shown in Figure S4. 

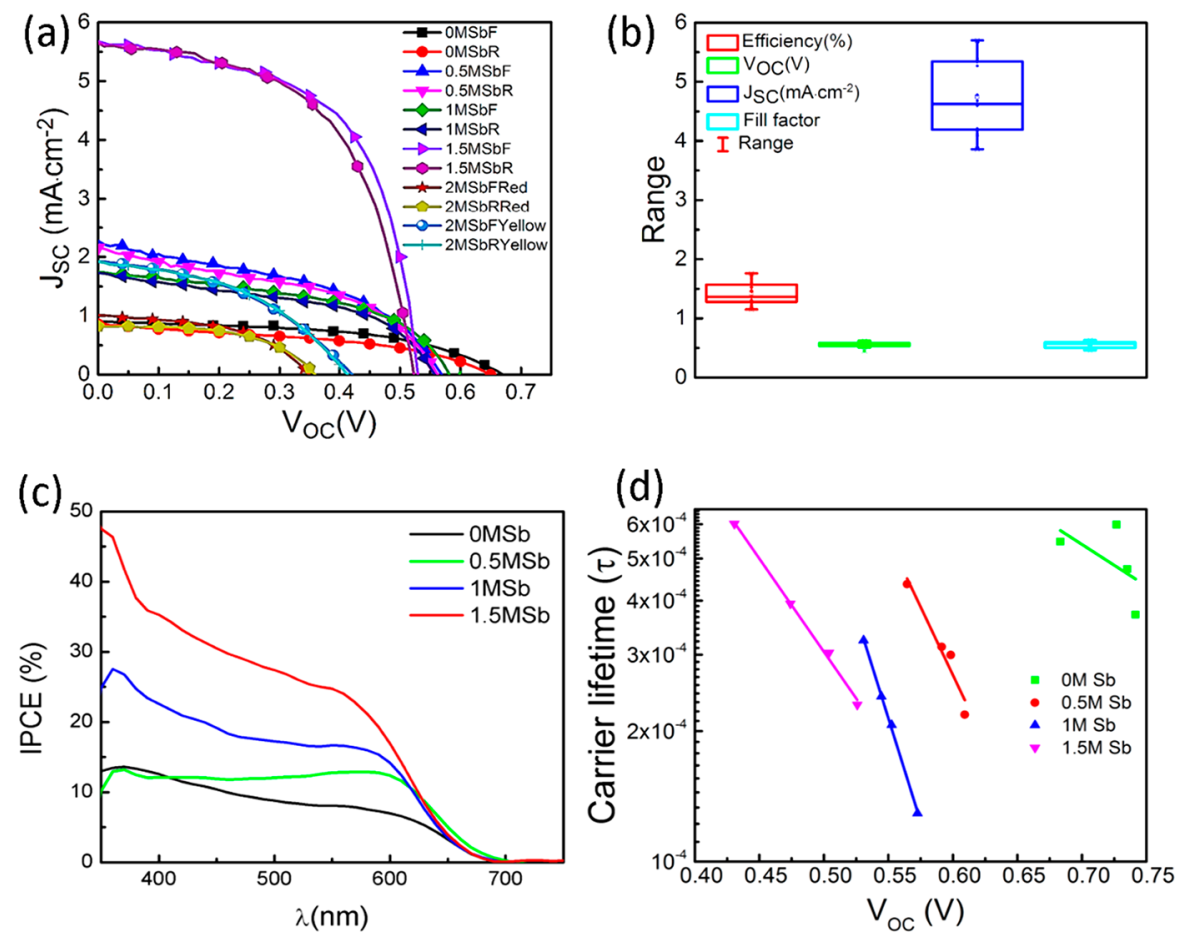

Figure 6. Forward and reverse $I-V$ scans for the samples (a), the photovoltaic parameters of 20 solar cells of $\mathrm{AgBi}_{0.5} \mathrm{Sb}_{1.5} \mathrm{I}_{7}$ (b), the IPCE measurements of $\mathrm{AgBi}_{0.5} \mathrm{Sb}_{1.5} \mathrm{I}_{7}$ solar cells (c), and the carrier lifetime measurement (d) for $\mathrm{AgBi}_{2-x} \mathrm{Sb}_{x} \mathrm{I}_{7}(x=0,0.5,1,1.5 \mathrm{M})$ samples.

Table 2. Photovoltaic Parameters of $\mathrm{AgBi}_{2-x} \mathrm{Sb}_{x} \mathrm{I}_{7}(x=0.5,1,1.5$, and 2) Solar Cells by Forward and Reverse Scans

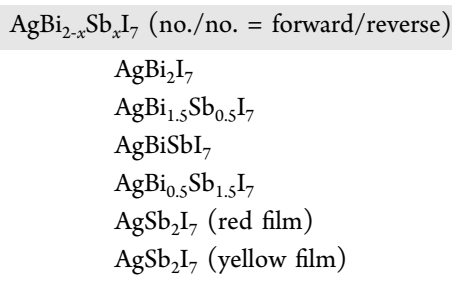

Figure 6 shows the results from characterization of the $\mathrm{AgBi}_{2} \mathrm{I}_{7^{-}}, \mathrm{AgBi}_{1.5} \mathrm{Sb}_{0.5} \mathrm{I}_{7^{-}}, \mathrm{AgBiSbI}_{7^{-}}, \mathrm{AgBi}_{0.5} \mathrm{Sb}_{1.5} \mathrm{I}_{7^{-}}$, and $\mathrm{AgSb}_{2} \mathrm{I}_{7}$-based solar cells. Figure $6 \mathrm{a}$ shows forward $(\mathrm{F})$ and reverse (R) current-voltage $(I-V)$ measurements of the different solar cells under illumination. The short-circuit current $\left(J_{\mathrm{SC}}\right)$ is higher for the samples with $\mathrm{Sb}$ mixed with $\mathrm{Bi}$ in the metal-halide material and the maximum short-circuit current is $5.66 \mathrm{~mA} \cdot \mathrm{cm}^{-2}$ for the $\mathrm{AgBi}_{0.5} \mathrm{Sb}_{1.5} \mathrm{I}_{7}$ solar cell. However, the $V_{\mathrm{OC}}$ decreases slightly when mixing in $\mathrm{Sb}$. The photovoltaic parameters of the best solar cell $\left(\mathrm{AgBi}_{0.5} \mathrm{Sb}_{1.5} \mathrm{I}_{7}\right)$ are $1.76 \%(\mathrm{PCE}), 0.53 \mathrm{~V}\left(V_{\mathrm{OC}}\right), 5.66 \mathrm{~mA} \cdot \mathrm{cm}^{-2}\left(J_{\mathrm{SC}}\right)$, and $59 \%$ (FF) (Table 2). The statistics of the photovoltaic parameters of 20 solar cells with $\mathrm{AgBi}_{0.5} \mathrm{Sb}_{1.5} \mathrm{I}_{7}$ can be seen in Figure 6b. The average PCE, $V_{\mathrm{OC}}, J_{\mathrm{SC}}$ and FF is $1.55 \%, 0.55 \mathrm{~V}, 5.0 \mathrm{~mA}$. $\mathrm{cm}^{-2}$, and $57 \%$ respectively. Stability measurement of $\mathrm{AgBi}_{0.5} \mathrm{Sb}_{1.5} \mathrm{I}_{7}$ is shown in Figure $\mathrm{S} 5.85 \%$ of the initial efficiency is retained after 43 days of storage in a drybox.

The incident photon-to-current conversion efficiency (IPCE) spectra for the different solar cell devices are shown in Figure 6c, which shows that the IPCE increases for the samples with higher content of $\mathrm{Sb}$, which agrees with the $I-V$ measurements above. Interestingly the onset for the photocurrent is around $700 \mathrm{~nm}$ for all samples, although the light absorption edge is different for the materials. For the solar cell without $\mathrm{Sb}$ in the metal-halide, we would expect an onset of

$\begin{array}{ccc}J_{\text {SC }}\left(\mathrm{mA} \cdot \mathrm{cm}^{-2}\right) & \text { FF }(\%) & \text { PCE }(\%) \\ 0.91 / 0.86 & 51 / 42 & 0.31 / 0.24 \\ 2.27 / 2.15 & 43 / 45 & 0.56 / 0.54 \\ 2.11 / 2.04 & 50 / 49 & 0.58 / 0.52 \\ 5.66 / 5.68 & 59 / 56 & 1.76 / 1.66 \\ 1.01 / 0.82 & 49 / 55 & 0.16 / 0.16 \\ 1.92 / 1.92 & 42 / 43 & 0.35 / 0.34\end{array}$

the IPCE at longer wavelength due to the smaller band gap energy. A possible explanation for this effect would be that the electron transfer from the metal-halide to $\mathrm{TiO}_{2}$ is inefficient for electrons with excitation energy close to the band gap. For the metal-halide without $\mathrm{Sb}$, the band gap energy is slightly smaller than the band gap for the mixed $\mathrm{Sb}$ and $\mathrm{Bi}$ metal-halides, and the electrons excited close to the band gap energy may in that case have too low energy to be able to inject into $\mathrm{TiO}_{2}$. With an increasing amount of $\mathrm{Sb}$ in the material, we observed in the UV-vis spectra in Figure 3 that the band gap energy increases. This could facilitate more efficient electron injection from the metal-halide to $\mathrm{TiO}_{2}$, which may also explain the increase in IPCE overall.

The lifetime of the photoinduced charges was investigated by transient photovoltage decay measurements and the results are shown in Figure 6d. Comparing the results for the different solar cells, there is no significant difference in the photocarrier lifetime between the devices. We therefore conclude that the differences in the photocurrent and the photovoltaic performance are probably not related to different charge carrier lifetime but rather due to a difference in charge injection from the metal-halides to the $\mathrm{TiO}_{2}$, which was suggested from the IPCE results above. 


\section{CONCLUSIONS}

In this work, new silver bismuth antimony iodide materials based on different proportions of bismuth and antimony are investigated. Starting from the previously investigated sample made with the precursor stoichiometry of $\mathrm{AgBi}_{2} \mathrm{I}_{7}, \mathrm{Bi}$ was partly exchanged with $\mathrm{Sb}$ to prepare mixed $\mathrm{Bi} / \mathrm{Sb}$ samples with the precursor stoichiometry $\mathrm{AgBi}_{2-x} \mathrm{Sb}_{x} \mathrm{I}_{7}(x=0,0.5,1,1.5,2)$. SEM images showed that the morphology of the films, as well as the grain size, were different for different amount of $S b$ in the materials. From the UV-vis measurements, it was concluded that the band gap is blue-shifted for an increasing amount of $\mathrm{Sb}$ in the materials, from $1.61 \mathrm{eV}$ for the material without $\mathrm{Sb}$, to $1.74 \mathrm{eV}$ for the material with $\mathrm{Sb} / \mathrm{Bi}$ ratio of 3 . The gradually blue-shifted absorption edge also agrees with a partial inclusion of $\mathrm{Sb}$ in the material and not formation of a second phase. The quantitative calculations from XRD and XPS measurements confirm that an expected amount of $S b$ has been mixed into the materials. However, there is a deficiency of iodide for all systems as measured from XPS, which may be from slight decomposition during the annealing process, which results in defects. Solar cells based on these materials were prepared, and for the samples where Bi was partly exchanged to $\mathrm{Sb}$, the photocurrent was significantly enhanced. The device based on $\mathrm{AgBi}_{0.5} \mathrm{Sb}_{1.5} \mathrm{I}_{7}$ showed the highest performance mainly due to an enhanced photocurrent compared to the devices based on pure Bi halides and Sb halides. Interestingly the IPCE spectra showed a similar onset even though the materials have different band gap energies, which may be due to problems with injection of electrons for excitation energies close to the band gap for the material without $\mathrm{Sb}$.

With the addition of SOC effects, the theoretical calculations reproduce the experimental trend in the bandgaps which is not seen when mere scalar relativistic effect are included. The SOC effects also reveal significant changes to the band structure, with the location of the direct band gap being displaced with increased $\mathrm{Sb}$ content.

Finally, we conclude that this work presents the possibility to enhance the space of new lead-free metal halides by mixing $\mathrm{Bi}$ and $\mathrm{Sb}$ in $\mathrm{AgBi}_{2-x} \mathrm{Sb}_{x} \mathrm{I}_{7}$ and that the mixed $\mathrm{Bi} / \mathrm{Sb}$ material show promising photovoltaic properties.

\section{EXPERIMENTAL METHODS}

$\mathrm{AgBi}_{2-x} \mathrm{Sb}_{x} \mathrm{I}_{7}$ Film Preparation. The precursor solutions of the $\mathrm{AgBi}_{2-x} \mathrm{Sb}_{x} \mathrm{I}_{7}$ systems $(x=0.5,1,1.5$, and 2$)$ were prepared by mixing the precursors of $\mathrm{AgI}$ (Sigma-Aldrich, 99\%), $\mathrm{BiI}_{3}$ (Alfa Aesar, 99.999\%), and $\mathrm{SbI}_{3}$ (Sigma-Aldrich, 98\%) without further purification. Then the powders were dissolved in mixed solvents of $\mathrm{N}, \mathrm{N}$ dimethylformamide (DMF) (Sigma-Aldrich, 99.8\%) and dimethyl sulfoxide (DMSO) (Sigma-Aldrich, $\geq 99 \%$ ) at a volume ratio of $1: 1$, the concentration of all the solutions was $26 \mathrm{wt} \%$. To obtain clear precursor solutions, the ultrasonic method was applied for $30 \mathrm{~min}$. Subsequently the solutions were spin-coated to the $\mathrm{TiO}_{2}$ substrates at $2000 \mathrm{rpm}$ for $60 \mathrm{~s}$ in the argon box. To form dark-color films, first, we annealed the film under $100{ }^{\circ} \mathrm{C}$ for $5 \mathrm{~min}$; second, the annealing temperature was raised to $125^{\circ} \mathrm{C}$, and the films were kept annealing for another $25 \mathrm{~min}$, yielding the crystallized films.

Solar Cell Fabrication. All the solar cells were fabricated with mesoporous structure on fluorine tin oxide (FTO) (Pilkington TEC $15,15 \mathrm{~T} / \mathrm{sq}$ ) glass. Zinc powder and $5 \mathrm{M} \mathrm{HCl}$ were used to etch the FTO. The etched FTO glass pieces were cleaned by RBS soap (sodium hydroxide, Sigma-Aldrich), acetone and ethanol under ultrasonic shaking, and each step lasted for $30 \mathrm{~min}$. The $\mathrm{TiO}_{2}$ precursor solution for the blocking layer was mixed by adding 1 $\mathrm{mL}$ of titanium(IV) isopropoxide (Sigma-Aldrich, 99.999\%), $3 \mathrm{~mL}$ of acetyl acetone (Sigma-Aldrich, analytical standard), and $12 \mathrm{~mL}$ of ethanol (Sigma-Aldrich, anhydrous). Through spray pyrolysis method, around $50 \mathrm{~nm}$ of a $\mathrm{TiO}_{2}$ blocking layer was deposited on the clean etched FTO substrates under $500{ }^{\circ} \mathrm{C}$ for $30 \mathrm{~min}$. A $\mathrm{TiO}_{2}$ commercial paste (Dyesol, 30NR-T) was used as the mesoporous layer of the solar cell. To prepare the precursor solution, $2 \mathrm{~g}$ of $\mathrm{TiO}_{2}$ paste was diluted by $7 \mathrm{~g}$ of ethanol. The precursor solution was stirred overnight before spin-coated it on the blocking layer. The spincoating speed of $\mathrm{TiO}_{2}$ solution was $4000 \mathrm{rpm}$ for $30 \mathrm{~s}$, after which the samples dried at $85{ }^{\circ} \mathrm{C}$ for $20 \mathrm{~min}$. The samples were moved into the oven and annealed at $500{ }^{\circ} \mathrm{C}$ for $30 \mathrm{~min}$ to form anatase $\mathrm{TiO}_{2}$. PTB7 (Borun New Material, China) with the concentration of $5 \mathrm{mg} / \mathrm{mL}$ in chlorobenzene was chosen as HTM which was spin-coated on the crystallized $\mathrm{AgBi}_{2-x} \mathrm{Sb}_{x} \mathrm{I}_{7}$ films under $2000 \mathrm{rpm}$ for $30 \mathrm{~s}$. In the last step, $10 \mathrm{~nm}$ of molybdenum trioxide $\left(\mathrm{MoO}_{3}\right)$ (Sigma-Aldrich, $\geq 99.5 \%$ ) and $80 \mathrm{~nm}$ of gold were evaporated onto this layer separately under $10^{-5}$ mbar.

Characterizations of the Films and Solar Cells. SEM. The surface morphology of the films was characterized with SEM employing a LEO 1550 FEG instrument with in-lens and a secondary electron detector operating at $10 \mathrm{kV}$.

UV-vis Spectra. The Lambda $900 \mathrm{UV} /$ vis/NIR spectrophotometers (PerkinElmer) with a double beam optical system was applied to scan the samples in the wavelength range of $300-2000 \mathrm{~nm}$. All the samples were prepared on the same mesoporous $\mathrm{TiO}_{2}$ film with the quartz glass. Using the following equation, the absorptance $(A, \%)$ was calculated from the transmittance $(T, \%)$ and reflectance $(R, \%)$, which were measured based on the reference measurement:

$$
A(\%)=1-T(\%)-R(\%)
$$

The indirect and direct band gap were derived using the Tauc plot method, where $a$ is the absorption coefficient and $d$ is the thickness of the light absorbing film. The indirect allowed transition and direct transition are determined by plotting $(a \cdot d \cdot h v)^{1 / n}$ against $h v$, for the direct allowed transition, the $n=1 / 2$, for the indirect allowed transition, the $n=2$. To get the absorption coefficient of the pure thin film $\left(a_{\text {film }}\right)$, the absorption coefficient of $\mathrm{TiO}_{2}$ glass $\left(a_{\text {glass }}\right)$ needs to be deducted:

$$
\alpha_{\text {film }} d_{\text {film }}=\alpha_{\text {total }} d_{\text {total }}-\alpha_{\mathrm{TiO}_{2}} d_{\mathrm{TiO}_{2}}
$$

$X R D$. All the samples were prepared on the blocking and mesoporous $\mathrm{TiO}_{2} / \mathrm{FTO}$ substrates. The XRD (Siemens D5000 $\theta-$ $2 \theta$ Diffractometer) was used to analyze the crystal structure and the phase content of the films. The instrument has the goniometer with a $\mathrm{Cu}-K \alpha(\lambda=1.54051 \AA)$ radiation and the Soller-Slit collimator of $0.4^{\circ}$ which had a resolution of $0.3^{\circ}(2 \theta)$ (Bruker AXS, Karlsruhe, Germany). Scans were recorded in the range from 5 to $80^{\circ}(2 \theta)$. The calculations for the approximate composition from XRD were derived from fitting the lattice parameters trends based on monophasic cubic $F d \overline{3} m$ and calculating the fractional numbers.

$P C E$. The setup for the power conversion efficiency measurements were published previously. ${ }^{29}$ The scanning speed was $100 \mathrm{mV} / \mathrm{s}$ under Air Mass $1.5 \mathrm{G}\left(1000 \mathrm{~W} \cdot \mathrm{m}^{-2}\right.$, light illumination $)$. The circular aperture area was $0.125 \mathrm{~cm}^{2}$.

IPCE. The setup for the incident photon to current conversion efficiency (IPCE) measurements were published previously. ${ }^{29}$ The wavelength was scanned from 330 to $900 \mathrm{~nm}$ and the photon flux calibration was performed with a standard silicon solar cell.

Carrier Lifetime Measurements. Carrier lifetimes of the solar cells are determined by tracking the $V_{\mathrm{OC}}$ decay under different light intensities. The method was published previously. ${ }^{44}$

XPS. A PHI Quantera II from Physical Electronics was used to measure XPS spectra of different films of different metal precursor ratios. A monochromatic $\mathrm{Al}-\mathrm{K} \alpha \mathrm{X}$-ray source with an output energy of $25 \mathrm{~W}(15 \mathrm{kV})$ was used with a band-pass energy of $112 \mathrm{eV}$ for the element measurements and $224 \mathrm{eV}$ for the survey over the whole energy range. An elemental analysis was made by integrating the areas under the peaks and using previously established sensitivity factors to receive the effective area and thus atomic fraction of each element. 
HAXPES. HAXPES measurements were performed at the synchrotron BESSY II, at the KMC-1 bending magnet beamline paired with the HIKE end-station. The incident photon energy was set to $4000 \mathrm{eV}$, using the Si (311) double crystal monochromatic, which yields an overall energy resolution of $250 \mathrm{meV}^{45}$ The HIKE end-station is equipped with a Scienta R4000 hemispherical electron analyzer; the incident angle between the beam and the surface of the sample was $\sim 5^{\circ}$, while the photoelectrons were detected close to normal emission, $\sim 85^{\circ}$. The pass energy of the R4000 was set to 500 $\mathrm{eV}$ for survey/overview scans and to $200 \mathrm{eV}$ for all other scans. Fermi edge calibration was performed by first acquiring HAXPES measurements of the gold foil mounted on the manipulator rod, then setting the peak position of the gold $4 \mathrm{f} 7 / 2$ core level to $84.0 \mathrm{eV}$ binding energy (BE). The pressure in the analysis chamber during measurements was $\sim 10^{-8}$ mbar.

The shallow core levels of bismuth $\left(5 \mathrm{~d}^{5 / 2}\right.$ at $\left.\sim 27 \mathrm{eV} \mathrm{BE}\right)$, iodine $\left(4 \mathrm{~d}^{5 / 2}\right.$ at $\left.\sim 50 \mathrm{eV} \mathrm{BE}\right)$, and antimony $\left(4 \mathrm{~d}^{5 / 2}\right.$ at $\left.\sim 36 \mathrm{eV} \mathrm{BE}\right)$ were selected for quantifying the chemical composition for two reasons. First, given a $4000 \mathrm{eV}$ excitation energy, the resulting photoelectron kinetic energies would be quite similar, eliminating the need to compensate for different probing depths. Second, the orbital symmetries ( $\mathrm{d}$ core-levels) are similar, which reduces the need to compensate for the anisotropic characteristics of the photoemission. The intensity ratios presented in the Supporting Information were calculated from the curve fits of the experimental spectra, after correcting for the photoionization cross sections using database values from Scofield. ${ }^{46}$

The fitting of the HAXPES spectra was complicated by the presence of interfering photoelectron peaks from the underlying $\mathrm{TiO}_{2}$ substrate, indicating that the films are discontinuous. In spite of this, there is sufficient structure in the spectra to fit the peaks of interest. However, because of the presence of interfering oxygen $2 \mathrm{~s}$ peaks in the bismuth $5 \mathrm{~d}$ spectra and interfering titanium $3 \mathrm{p}$ peaks in the antimony $4 \mathrm{~d}$ spectra, the variations in the fwhm and LorentzianGaussian\% are larger for the fitted bismuth $5 \mathrm{~d}$ and antimony $4 \mathrm{~d}$ peaks than for the iodine $4 \mathrm{~d}$ peaks. The Lorentzian-Gaussian\% ranges from $0 \%$ (pure Gaussian) to $100 \%$ (pure Lorentzian). All bismuthcontaining compounds showed the presence of metallic bismuth (Bi $4 \mathrm{f}^{7 / 2}$ peak position for metallic bismuth is at $2 \mathrm{eV}$ lower binding energy versus the peak position for bismuth bonded to iodide). The metallic bismuth was not included in the ratio calculations.

Density Functional Theory. Electronic structure calculations were performed on five different $\mathrm{Bi} / \mathrm{Sb}$ compositions ranging from $\mathrm{AgBi}_{2} \mathrm{I}_{7}$ to $\mathrm{AgSb}_{2} \mathrm{I}_{7}$ in steps of $25 \%$ using density functional theory (DFT).

The model of the cubic $\mathrm{AgBi}_{2} \mathrm{I}_{7}$ system in this work is adapted from previous work, ${ }^{47}$ which suggests that $\mathrm{AgBi}_{2} \mathrm{I}_{7}$ has the same structure as the cubic $F d \overline{3} m \mathrm{AgBiI}_{4}$ crystal with a lattice parameter of $12.223 \AA$, but with different lattice site occupations thus yielding a different stoichiometry. The unit cell contains $5 \mathrm{Ag}, 9 \mathrm{Bi}$, and $32 \mathrm{I}$, as well as two cation vacancies, and it is not obvious how the cations and vacancies should be distributed within the cell. Because of this, different configurations of the unit cell needed to be investigated. By placing the cations differently, the face-centered cubic symmetry is lost, and only simple cubic symmetry is retained. Placing the cations randomly in the cation lattice sites, a set of 25 realizations were generated but inspecting the optimized structures revealed that some of them had significantly lower energy and a less distorted geometry than others. The configurations with the high energy resulted in $\mathrm{Ag}$ atoms partially or completely leaving their sites and forming clusters, also producing extremely small bandgaps. The variance in energy is strongly related to the relative positions of the $\mathrm{Ag}$ atoms and the vacancies and this effect of diffusion will be investigated in a future study. In this work, a single low-energy configuration of cations and vacancies where the $\mathrm{Ag}$ atoms are relatively stable under optimization is used for all calculations. The initial coordinates of this configuration is shown in Table S4. Note that the anion positions are unambiguous. To obtain the composition with different $\mathrm{Sb}$ content, $\mathrm{Bi}$ atoms were randomly substituted for $\mathrm{Sb}$ until the desired ratio was obtained.
For the band structure calculations, a unit cell representation with $k$-point sampling was employed, while for the density of states (DOS), a $2 \times 2 \times 2$ super cell representation of the unit cell at the $\Gamma$ point was used. In the super cell case, a total of five different realizations for each sample is considered to take into account the effects of the different ways to distribute the $\mathrm{Sb}$, and the average cell parameter and DOS are presented. Since the band structure calculations involving SOC effects are more demanding, only a single realization for each composition is used. This can be motivated with the observation that the DOS results vary only slightly over the different realizations.

The cell parameter and atomic coordinates were optimized with the CP2K package ${ }^{45}$ and the Quickstep (QS) $\operatorname{code}^{48}$ which uses the Gaussian and plane waves (GPW) method and Godecker-TeterHutter (GTH) pseudopotentials. ${ }^{49,50}$ During the optimization, only the cubic symmetry of the simulation cell was constrained while the atoms were allowed relax freely. The DFT functional used was PBE augmented with van der Waals interactions, ${ }^{51,52}$ and for the unit cell calculations, we employed a mesh of $27 \mathrm{k}$-points generated by the Monkhorst-Pack scheme. ${ }^{53}$ A local Gaussian TZVP basis set (generated following ${ }^{54}$ and distributed with the $\mathrm{CP} 2 \mathrm{~K}$ program) was used to expand the Kohn-Sham orbitals, while a plane-wave basis set with an energy cutoff of $600 \mathrm{Ry}$ was used to describe the electron density. From the super cell calculations, the DOS and projected density of states (PDOS) for both the different elements as well as the orbital angular momenta is extracted. The Kohn-Sham orbitals are interpreted as the photoelectron spectra and associating the orbital energies of the occupied orbitals with the electron binding energies. The obtained DOS was convolved with a Gaussian function with a full width at half-maximum of $0.4 \mathrm{eV}$ to allow for comparison with experimental measurements and ad hoc shifted so that zero energy is in the middle of the HOMO-LUMO gap.

To include spin-orbit coupling effects, single-point calculations in the QUANTUM ESPRESSO (QE) package ${ }^{55}$ are performed on the optimized unit cells (optimized in CP2K but confirmed to have small forces in $\mathrm{QE}$ ) employing fully relativistic pseudopotentials for $\mathrm{Bi}$ and $\mathrm{Sb}$. This is motivated by the fact that $\mathrm{Bi}$ is the heaviest atom in the systems and the SOC is expected to be stronger because of this, whereas $\mathrm{SOC}$ for $\mathrm{Sb}$ is included for a balanced comparison. These calculations are carried out using Rappe-Rabe-Kaxiras-Joannopoulos ultrasoft pseudopotential, including nonlinear core corrections, available in QE pseudopotential library. ${ }^{56,57}$ As before, the PBE functional $^{52}$ is used as exchange-correlation functional and the planewave energy cutoffs were chosen as $40 \mathrm{Ry}$ for the electronic wave function and $455 \mathrm{Ry}$ for the change density. The same $k$-point mesh of 27 points as described above was used and the full band structure was extracted. An ad hoc shift is applied to the band energies to place the zero energy in the middle of the band gap.

\section{ASSOCIATED CONTENT}

\section{Supporting Information}

The Supporting Information is available free of charge at https://pubs.acs.org/doi/10.1021/acsaem.0c00712.

$\mathrm{Sb}$ composition confirmation by XRD and HAXPES of $\mathrm{AgBi}_{2-x} \mathrm{Sb}_{x} \mathrm{I}_{7}(x=0,0.5,1,1.5$, and 2) materials, HAXPES spectrum of the $\mathrm{AgBi}_{2-x} \mathrm{Sb}_{x} \mathrm{I}_{7}$ materials, fitted data, the fitted and expected materials compositions from XPS and HAXPES, theoretic calculation of the direct and indirect band gaps calculation without SOC effects, calculations of atomic coordinates of the cation configuration, SEM cross section of a full solar device, and stability measurements of $\mathrm{AgBi}_{2-x} \mathrm{Sb}_{x} \mathrm{I}_{7}$ solar cells (PDF) 


\section{AUTHOR INFORMATION}

\section{Corresponding Authors}

Michael Odelius - Department of Physics, Stockholm University, 10691 Stockholm, Sweden; 이이.org/00000002-7023-2486; Email: odelius@fysik.su.se

Erik M. J. Johansson - Department of Chemistry, Ångström Laboratory, Division of Physical Chemistry, Uppsala University,

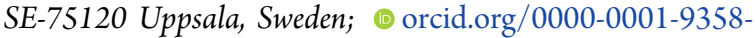
8277; Email: erik.johansson@kemi.uu.se

\section{Authors}

Huimin Zhu - Department of Chemistry, Angström Laboratory, Division of Physical Chemistry, Uppsala University, SE-75120 Uppsala, Sweden

Axel Erbing - Department of Physics, Stockholm University, 10691 Stockholm, Sweden

Hua Wu - Department of Chemistry, Angström Laboratory, Division of Physical Chemistry, Uppsala University, SE-75120 Uppsala, Sweden; State Key Laboratory on Integrated Optoelectronics and College of Electronic Science and Engineering, Jilin University, Changchun 130012, China

Gabriel J. Man - Department of Physics and Astronomy, The Physics of Molecular and Condensed Matter, Uppsala University, SE-75120 Uppsala, Sweden

Soham Mukherjee - Department of Physics and Astronomy, The Physics of Molecular and Condensed Matter, Uppsala University, SE-75120 Uppsala, Sweden

Chinnathambi Kamal - Department of Physics, Stockholm University, 10691 Stockholm, Sweden; Theory and Simulations Laboratory, HRDS, Raja Ramanna Centre for Advanced Technology, Indore 452013, India

Malin B. Johansson - Department of Chemistry, Angström Laboratory, Division of Physical Chemistry, Uppsala University, SE-75120 Uppsala, Sweden; 이 orcid.org/0000-0003-20461229

Håkan Rensmo - Department of Physics and Astronomy, The Physics of Molecular and Condensed Matter, Uppsala University, SE-75120 Uppsala, Sweden

Complete contact information is available at: https://pubs.acs.org/10.1021/acsaem.0c00712

\section{Author Contributions}

${ }^{\#}$ Z.H. and A.E. contributed equally to the work.

\section{Notes}

The authors declare no competing financial interest.

\section{ACKNOWLEDGMENTS}

We acknowledge financial support obtained from the Swedish Energy Agency, Swedish Research Council (V.R.), and Olle Engkvist Foundation. H.Z. and H.W. gratefully acknowledges the China Scholarship Council (CSC) for Ph.D. study fellowships. The calculations were performed on resources provided by the Swedish National Infrastructure for Computing (SNIC).

\section{REFERENCES}

(1) NREL. Best Research-Cell Efficiency Chart, 2020. https://www. nrel.gov/pv/cell-efficiency.html.

(2) Kojima, A.; Teshima, K.; Shirai, Y.; Miyasaka, T. Organometal Halide Perovskites as Visible-Light Sensitizers for Photovoltaic Cells. J. Am. Chem. Soc. 2009, 131, 6050-6051.
(3) Lee, M. M.; Teuscher, J.; Miyasaka, T.; Murakami, T. N.; Snaith, H. J. Efficient Hybrid Solar Cells Based on Meso-Superstructured Organometal Halide Perovskites. Science 2012, 338, 643-647.

(4) Kim, H.-S.; Lee, C.-R.; Im, J.-H.; Lee, K.-B.; Moehl, T.; Marchioro, A.; Moon, S.-J.; Humphry-Baker, R.; Yum, J.-H.; Moser, J. E.; Grätzel, M.; Park, N.-G. Lead iodide perovskite sensitized all-solidstate submicron thin film mesoscopic solar cell with efficiency exceeding 9\%. Sci. Rep. 2012, 2, 591.

(5) Huang, F.; Li, M.; Siffalovic, P.; Cao, G.; Tian, J. Scalable solution fabrication of perovskite films towards commercialization of solar cells. Energy Environ. Sci. 2019, 12, 518-549.

(6) Hao, F.; Stoumpos, C. C.; Cao, D. H.; Chang, R. P. H.; Kanatzidis, M. G. Lead-free solid-state organic-inorganic halide perovskite solar cells. Nat. Photonics 2014, 8, 489-494.

(7) Wang, X.; Zhang, T.; Lou, Y.; Zhao, Y. All-inorganic lead-free perovskites for optoelectronic applications. Materials Chemistry Frontiers 2019, 3, 365-375.

(8) Krishnamoorthy, T.; Ding, H.; Yan, C.; Leong, W. L.; Baikie, T.; Zhang, L.; Sherburne, M. P.; Li, S.; Asta, M.; Mathews, N.; Mhaisalkar, S. G. Lead-free Germanium Iodide Perovskite Materials for Photovoltaic Application. J. Mater. Chem. A 2015, 3, 2382923832.

(9) Chen, L. Synthesis and optical properties of lead-free cesium germanium halide perovskite quantum rods. RSC $A d v$. 2018, 8, 18396-18399.

(10) Park, B.; Philippe, B.; Zhang, X.; Rensmo, H.; Boschloo, G.; Johansson, E. M. J. Bismuth Based Hybrid Perovskites $\mathrm{A}_{3} \mathrm{Bi}_{2} \mathrm{I}_{9}$ (A: Methylammonium or Cesium) for Solar Cell Application. Adv. Mater. 2015, 27, 6806-6813.

(11) Hodgkins, T.; Savory, C. N.; Bass, K. K.; Seckman, B. L.; Scanlon, D. O.; Djurovich, P. I.; Thompson, M.; Melot, B. Anionic order and band gap engineering in vacancy ordered triple perovskites. Chem. Commun. (Cambridge, U. K.) 2019, 55, 3164-3167.

(12) Yu, B.; Liao, M.; Yang, J.; Chen, W.; Zhu, Y.; Zhang, X.; Duan, T.; Yao, W.; Wei, S.; He, Z. Alloy-induced phase transition and enhanced photovoltaic performance: the case of $\mathrm{Cs}_{3} \mathrm{Bi}_{2} \mathrm{I}_{9-\mathrm{x}} \mathrm{Br}_{\mathrm{x}}$ perovskite solar cells. J. Mater. Chem. A 2019, 7, 8818-8825.

(13) Adonin, S. A.; Frolova, L. A.; Sokolov, M. N.; Shilov, G. V.; Korchagin, D. V.; Fedin, V. P.; Aldoshin, S. M.; Stevenson, K. J.; Troshin, P. A. Antimony (V) Complex Halides: Lead-Free PerovskiteLike Materials for Hybrid Solar Cells. Adv. Energy Mater. 2018, 8, 1701140 .

(14) Chen, M.; Ju, M.; Carl, A. D.; Zong, Y.; Grimm, R. L.; Gu, J.; Zeng, X.; Zhou, Y.; Padture, N. P. Cesium Titanium(IV) Bromide Thin Films Based Stable Lead-free Perovskite Solar Cells. Joule 2018, $2,558-570$.

(15) Chen, M.; Ju, M.; Garces, H. F.; Carl, A. D.; Ono, L. K.; Hawash, Z.; Zhang, Y.; Shen, T.; Qi, Y.; Grimm, R. L.; Pacifici, D.; Zeng, X.; Zhou, Y.; Padture, N. P. Highly stable and efficient allinorganic lead-free perovskite solar cells with native-oxide passivation. Nat. Commun. 2019, 10, 16.

(16) Shao, S.; Liu, J.; Portale, G.; Fang, H.-H.; Blake, G. R.; ten Brink, G. H.; Koster, L. J. A.; Loi, M. A. Highly Reproducible SnBased Hybrid Perovskite Solar Cells with 9\% Efficiency. Adv. Energy Mater. 2018, 8, 1702019.

(17) Grancini, G.; Roldan-Carmona, C.; Zimmermann, I.; Mosconi, E.; Lee, X.; Martineau, D.; Narbey, S.; Oswald, F.; De Angelis, F.; Gräetzel, M.; Nazeeruddin, M. K. One-Year stable perovskite solar cells by 2D/3D interface engineering. Nat. Commun. 2017, 8, 15684.

(18) Jokar, E.; Chien, C.-H.; Tsai, C.-M.; Fathi, A.; Diau, E. W.-G. Robust Tin-Based Perovskite Solar Cells with Hybrid Organic Cations to Attain Efficiency Approaching 10\%. Adv. Mater. 2019, 31, No. e1804835.

(19) Li, F.; Zhang, C.; Huang, J.; Fan, H.; Wang, H.; Wang, P.; Zhan, C.; Liu, C.; Li, X.; Yang, L.; Song, Y.; Jiang, K. A CationExchange Approach for the Fabrication of Efficient Methylammonium Tin Iodide Perovskite Solar Cells. Angew. Chem., Int. Ed. 2019, 58, $6688-6692$ 
(20) Babayigit, A.; Ethirajan, A.; Muller, M.; Conings, B. Toxicity of organometal halide perovskite solar cells. Nat. Mater. 2016, 15, 247251.

(21) Drury, B. N. Formation of Potential Tandem Junction Photovoltaic Materials for Silicon, 2018. https://digitalcommons.wpi. $\mathrm{edu} / \mathrm{mqp}$-all/1825.

(22) Harikesh, P. C.; Mulmudi, H. K.; Ghosh, B.; Goh, T. W.; Teng, Y. T.; Thirumal, K.; Lockrey, M.; Weber, K.; Koh, T. M.; Li, S.; Mhaisalkar, S.; Mathews, N. Rb as an Alternative Cation for Templating Inorganic Lead-Free Perovskites for Solution Processed Photovoltaics. Chem. Mater. 2016, 28, 7496-7504.

(23) Li, Y.-J.; Wu, T.; Sun, L.; Yang, R.-X.; Jiang, L.; Cheng, P.-F.; Hao, Q.-Q.; Wang, T.-J.; Lu, R.-F.; Deng, W.-Q. Lead-free and stable antimony-silver-halide double perovskite $\left(\mathrm{CH}_{3} \mathrm{NH}_{3}\right)_{2} \mathrm{AgSbI}_{6}$. RSC Adv. 2017, 7, 35175-35180.

(24) Greul, E.; Petrus, M. L.; Binek, A.; Docampo, P.; Bein, T. Highly stable, phase pure $\mathrm{Cs}_{2} \mathrm{AgBiBr}_{6}$ double perovskite thin films for optoelectronic applications. J. Mater. Chem. A 2017, 5, 19972-19981.

(25) Giustino, F.; Snaith, H. J. Toward Lead-Free Perovskite Solar Cells. ACS Energy Letters 2016, 1, 1233-1240.

(26) Volonakis, G.; Filip, M. R.; Haghighirad, A. A.; Sakai, N.; Wenger, B.; Snaith, H. J.; Giustino, F. Lead-Free Halide Double Perovskites via Heterovalent Substitution of Noble Metals. J. Phys. Chem. Lett. 2016, 7, 1254-1259.

(27) Slavney, A. H.; Leppert, L.; Bartesaghi, D.; Gold-Parker, A.; Toney, M. F.; Savenije, T. J.; Neaton, J. B.; Karunadasa, H. I. DefectInduced Band-Edge Reconstruction of a Bismuth-Halide Double Perovskite for Visible-Light Absorption. J. Am. Chem. Soc. 2017, 139, 5015-5018.

(28) Turkevych, I.; Kazaoui, S.; Ito, E.; Urano, T.; Yamada, K.; Tomiyasu, H.; Yamagishi, H.; Kondo, M.; Aramaki, S. Photovoltaic Rudorffites: Lead-Free Silver Bismuth Halides Alternative to Hybrid Lead Halide Perovskites. ChemSusChem 2017, 10, 3754-3759.

(29) Zhu, H.; Pan, M.; Johansson, M. B.; Johansson, E. M. J. High Photon-to-Current Conversion in Solar Cells Based on LightAbsorbing Silver Bismuth Iodide. ChemSusChem 2017, 10 (12), $2592-2596$.

(30) Kim, Y.; Yang, Z.; Jain, A.; Voznyy, O.; Kim, G.-H.; Liu, M.; Quan, L. N.; García de Arquer, F. P.; Comin, R.; Fan, J. Z.; Sargent, E. $\mathrm{H}$. Pure Cubic-Phase Hybrid Iodobismuthates $\mathrm{AgBi}_{2} \mathrm{I}_{7}$ for Thin-Film Photovoltaics. Angew. Chem., Int. Ed. 2016, 55, 9586-9590.

(31) Shao, Z.; Le Mercier, T.; Madec, M.B.; Pauporté, Th. Exploring $\mathrm{AgBi}_{\mathrm{x}} \mathrm{I}_{3 \mathrm{x}+1}$ semiconductor thin films for lead-free perovskite solar cells. Mater. Des. 2018, 141, 81-87.

(32) Shao, Z.; Le Mercier, T.; Madec, M. B.; Pauporté, T. $\mathrm{AgBi}_{2} \mathrm{I}_{7}$ layers with controlled surface morphology for solar cells with improved charge collection. Mater. Lett. 2018, 221, 135-138.

(33) Ghosh, B.; Wu, B.; Guo, X.; Harikesh, P. C.; John, R. A.; Baikie, T.; Arramel; Wee, A. T. S.; Guet, C.; Sum, T. C.; Mhaisalkar, S.; Mathews, N. Superior Performance of Silver Bismuth Iodide Photovoltaics Fabricated via Dynamic Hot-Casting Method under Ambient Conditions. Adv. Energy Mater. 2018, 8, 1802051.

(34) Lu, C.; Zhang, J.; Sun, H.; Hou, D.; Gan, X.; Shang, M.-h.; Li, Y.; Hu, Z.; Zhu, Y.; Han, L. Inorganic and Lead-Free $\mathrm{AgBiI}_{4}$ Rudorffite for Stable Solar Cell Applications. ACS Applied Energy Materials 2018, 1, 4485-4492.

(35) Harikesh, P. C.; Wu, B.; Ghosh, B.; John, R. A.; Lie, S.; Thirumal, K.; Wong, L. H.; Sum, T. C.; Mhaisalkar, S.; Mathews, N. Doping and Switchable Photovoltaic Effect in Lead-Free Perovskites Enabled by Metal Cation Transmutation. Adv. Mater. 2018, 30, 1802080.

(36) Saparov, B.; Hong, F.; Sun, J.; Duan, H.; Meng, W.; Cameron, S.; Hill, I. G.; Yan, Y.; Mitzi, D. B. Thin-Film Preparation and Characterization of $\mathrm{Cs}_{3} \mathrm{Sb}_{2} \mathrm{I}_{9}$ : A Lead-Free Layered Perovskite Semiconductor. Chem. Mater. 2015, 27, 5622-5632.

(37) Jung, K.; Sohn, M.; Lee, H.; Yang, I.; Sung, S.; Kim, J.; Diau, E. W.-G.; Lee, W. Silver bismuth iodides in various compositions as potential $\mathrm{Pb}$-free light absorbers for hybrid solar cells. Sustainable Energy \& Fuels 2018, 2, 294-302.
(38) Khazaee, M.; Sardashti, K.; Chung, C.-C.; Sun, J.-P.; Zhou, H.; Bergmann, E.; Dunlap-Shohl, W. A.; Han, Q.; Hill, I. G.; Jones, J. L.; Lupascu, D. C.; Mitzi, D. B. Dual-source evaporation of silver bismuth iodide films for planar junction solar cells. J. Mater. Chem. A 2019, 7, 2095-2105.

(39) Kulkarni, A.; Jena, A.; Ikegami, M.; Miyasaka, T. Performance Enhancement of $\mathrm{AgBi}_{2} \mathrm{I}_{7}$ Solar Cells by Modulating the SolventMediated Adduct and Tuning Remnant $\mathrm{BiI}_{3}$ on One-step Crystallization. Chem. Commun. 2019, 55, 4031-4034.

(40) Wagner, C. D.; Davis, L. E.; Zeller, M. V.; Taylor, J. A.; Raymond, R. H.; Gale, L. H. Empirical atomic sensitivity factors for quantitative analysis by electron spectroscopy for chemical analysis. Surf. Interface Anal. 1981, 3, 211.

(41) Huq, T. N.; Lee, L. C.; Eyre, L.; Li, W.; Jagt, R. A.; Kim, C.; Fearn, S.; Pecunia, V.; Deschler, F.; MacManus-Driscoll, J.; Hoye, R. L. Z. Electronic Structure and Optoelectronic Properties of Bismuth Oxyiodide Robust against Percent-Level Iodine-, Oxygen-, and Bismuth-Related Surface Defects. Adv. Funct. Mater. 2020, 30 (13), 1909983.

(42) Xiao, Z.; Meng, W.; Mitzi, D. B.; Yan, Y. Crystal Structure of $\mathrm{AgBi}_{2} \mathrm{I}_{7}$ Thin Films. J. Phys. Chem. Lett. 2016, 7, 3903-3907.

(43) Coulter, J. B.; Birnie, D. P. Assessing Tauc Plot Slope Quantification: ZnO Thin Films as a Model System. Phys. Status Solidi B 2018, 255, 1700393.

(44) Zhu, H.; Johansson, M. B.; Johansson, E. M. J. The Effect of Dopant-Free Hole-Transport Polymers on Charge Generation and Recombination in Cesium-Bismuth-Iodide Solar Cells. ChemSusChem 2018, 11 (6), 1114-1120.

(45) Knut, R.; Lindblad, R.; Gorgoi, M.; Rensmo, H.; Karis, O. High energy photoelectron spectroscopy in basic and applied science: Bulk and interface electronic structure. J. Electron Spectrosc. Relat. Phenom. 2013, 190, 278-288.

(46) Scofield, J. H. United States: 1973. Theoretical photoionization cross sections from 1 to $1500 \mathrm{keV}$. Office of Scientific and Technical Information 1973, No. UCRL-51326.

(47) https://www.cp2k.org/.

(48) Krack, M. Pseudopotentials for $\mathrm{H}$ to $\mathrm{Kr}$ optimized for gradientcorrected exchange-correlation functionals. Theor. Chem. Acc. 2005, $114,145-152$.

(49) Goedecker, S.; Teter, M.; Hutter, J. Separable dual-space Gaussian pseudopotentials. Phys. Rev. B: Condens. Matter Mater. Phys. 1996, 54, 1703-1710.

(50) Grimme, S.; Ehrlich, S.; Goerigk, L. Effect of the Damping Function in Dispersion Corrected Density Functional Theory. J. Comput. Chem. 2011, 32, 1456-1465.

(51) VandeVondele, J.; Hutter, J. Gaussian basis sets for accurate calculations on molecular systems in gas and condensed phases. J. Chem. Phys. 2007, 127, 114105.

(52) Perdew, J. P.; Burke, K.; Ernzerhof, M. Generalized gradient approximation made simple. Phys. Rev. Lett. 1996, 77 (18), 38653868.

(53) VandeVondele, J.; Krack, M.; Mohamed, F.; Parrinello, M.; Chassaing, T.; Hutter, J. QUIKSTEP: Fast and accurate density functional calculations using a mixed Gaussian and plane waves approach. Comput. Phys. Commun. 2005, 167, 103-128.

(54) Monkhorst, H. J.; Pack, J. D. Special Points for Brillouin-Zone Integrations. Phys. Rev. B 1976, 13, 5188-5192.

(55) Giannozzi, P; Andreussi, O; Brumme, T; Bunau, O; Buongiorno Nardelli, M; Calandra, M; Car, R; Cavazzoni, C; Ceresoli, D; Cococcioni, M; Colonna, N; Carnimeo, I; Dal Corso, A; de Gironcoli, S; Delugas, P; DiStasio, R A; Ferretti, A; Floris, A; Fratesi, G; Fugallo, G; Gebauer, R; Gerstmann, U; Giustino, F; Gorni, T; Jia, J; Kawamura, M; Ko, H-Y; Kokalj, A; Kucukbenli, E; Lazzeri, M; Marsili, M; Marzari, N; Mauri, F; Nguyen, N L; Nguyen, H-V; Otero-de-la-Roza, A; Paulatto, L; Ponce, S; Rocca, D; Sabatini, R; Santra, B; Schlipf, M; Seitsonen, A P; Smogunov, A; Timrov, I; Thonhauser, T; Umari, P; Vast, N; Wu, X; Baroni, S Advanced capabilities for materials modelling with Quantum ESPRESSO. J. Phys.: Condens. Matter 2017, 29, 465901. 
(56) Rappe, A. M.; Rabe, K. M.; Kaxiras, E.; Joannopoulos, J. D. Optimized pseudopotentials. Phys. Rev. B: Condens. Matter Mater. Phys. 1990, 41, 1227.

(57) www.quantum-espresso.org/pseudopotentials. 